\title{
Extending the Task-Technology Fit (TTF) Model to E-Textbook Usage by Students and Instructors
}

\author{
Jo R. Jardina, Wichita State University, USA \\ Barbara S. Chaparro, Wichita State University, USA \\ Sue Abdinnour, Wichita State University, USA
}

\begin{abstract}
Companies produce increasing numbers of textbooks in electronic format (e-textbooks) for use by students and instructors. One would be remiss, however, to think that university bookstores are not filled with hard copies of textbooks; many students and instructors still insist on using traditional paper copy textbooks. Many models exist to explain the factors that influence whether users adopt new technologies. The majority of this research, however, focuses on a single user group or isolated new technologies in the academic domain, such as learning management systems or digital video tools. The study extends the Task-Technology Fit (TTF) model to explore how both students and instructors use e-textbooks. New items were added to existing constructs of access, task technology fit, and perceived ease of use. The authors propose a new model and test the impact of perceived ease of use, access to technology, and the task technology fit on performance by both students and instructors. The results of factor analysis and structural equation modeling are reported.
\end{abstract}

\section{KEYWORDS}

Acceptance to E-Textbooks, E-Learning, Online Reading, Online Studying

\section{INTRODUCTION}

One of the first universities that conducted surveys, interviews, and focus groups on e-Textbooks in and out of the classroom was Indiana University. In 2010, Indiana University conducted a series of studies investigating e-Textbook usage with undergraduates, graduates, and instructors in different departments. They found that students thought the e-Textbook was easy to use, and claimed they read more of the book when using the e-Textbook. Also, the students said having access to the instructors' highlights and notes was much more valuable to them than having access to others students' notes. However, instructors did not expect the students to read the textbook and therefore did not use it to its full teaching potential.

Indiana University's (2012)'s findings suggest that students do not annotate and highlight because instructors do not model this behavior. They claimed that an engaged instructor is critical 
to the success of the digital material. Usability of the e-Textbook is a high priority, as students who struggle with how to use the e-Textbook device will not use it, and it needs to have all the core features (highlighting, zooming, paging, etc.).

McKelvain (2011) investigated the use of features such as highlighting and annotating on an e-Textbook for writing and studying tasks. Their results showed that students highlighted frequently, but would often use outside materials (e.g. notecards, notepads, word processing document, etc.) instead of the annotation feature of the e-Textbook. This has been shown to be true for a variety of devices for textbook access, including the iPod Touch and cell phone (Chao \& Chen, 2009; Johnson, Levine, Smith, \& Stone, 2010).

Differences have been found in how people read digital text versus printed material. Liu (2005) found that when reading digital text, users report they are more likely to browse the material and scan for keywords but highlight and annotate less. Berg et al., (2010) reported that undergraduates adopt a less linear strategy when reading an e-Book than a printed book. The reading strategy also differs when reading for leisure (i.e., novels) than when reading a textbook. During leisure reading, readers typically read from beginning to end and do not focus on marking or annotating specific material. During textbook usage, readers are more likely to skim, scan, and navigate non-sequentially through the textbook to find information (Berry, Cook, Hill, \& Stevens, 2011; Horney \& Anderson-Inman, 1994; Wandersee, 1988). However, Weisberg (2011) compared several different e-Reading devices to paper books and found that while students preferred the paper books more, over time they became more and more receptive to the e-Reading devices.

Readers may use navigation features in a regular book differently than an e-Book, like Table of Contents, Index, and search capability. Abdullah and Gibbs (2008) found that readers consistently, and successfully, used an index when reading a paper book but did not realize an index was even available when using the e-Book.

Students may conduct tasks (e.g. bookmaking and highlighting) differently in an e-Book as opposed to a paper book. In a study examining reading strategies on an e-Textbook on a Nook e-Reader, Schugar, Schugar, and Penny (2011) found that students were less likely to highlight and take notes on the Nook than they were on the traditional textbook. Bookmarking pages, however, was reported to be done about as much as folding the corner of pages down in a traditional book. It is thought that the lack of annotation and highlighting activity could be attributed to a "steep learning curve" of how to use the features on the Nook.

As more schools and students switch to using e-Textbooks instead of traditional textbooks, it is important to understand how the user interface design and implementation of advanced features facilitates the strategies students employ when studying. In the next section, we look at the previous literature on e-Textbooks and the existing technology models to better understand the history of e-Textbooks usage by students and instructors. Then, we discuss our newly proposed model for e-Textbook usage, and explain how our newly proposed model provides new insights on e-Textbook adoption. We conclude with limitations and future research ideas.

\section{LITERATURE REVIEW}

In this section, we will discuss the challenges to introducing e-Textbooks, the factors that influence the use of e-Textbooks, and the existing technology models that have been used to study the use of e-Textbooks by students and instructors.

\section{Challenges to Introducing e-Textbooks}

With all the changes in technology and education come challenges. Introducing e-Textbooks into the classroom can introduce new usability issues and problems with usage of the novel technology. A study from Lee and Yau (2015) aimed to provide ideas for future e-Textbooks which may lead to the usage of the technology by students. In their study, instructor interviews were used to develop a 
new e-Textbook application and a short study was conducted on students with the newly developed e-Textbook application. They discovered four challenges when evaluating the application with students. The authors suggest that a challenge to e-Textbook usage is improving the quality and accuracy of content, which they believe can be solved with cloud computing and open market places. Another challenge is improving readability which they believe can be remedied by making the systems more user-friendly. The authors also propose that N-Screen services and HTML5 can help with standardizing the format of the e-Text content and P2P between screens. Lee and Yau's (2015) solutions are general and do not address specific usability or usage problems, but they do touch on many issues that face e-Textbook usage.

Morrone and Dennis (2010) from Indiana University found relationships between usage of the e-Textbooks and course grades. They found that, on average, students who used fewer text tools, such as highlighting and annotations, had a lower course grade. Kalic (2013) found that algebra students in a special needs class had a slight increase in achievement, participation, and peer collaboration when iPads were integrated into the classroom. However, teachers noted that students were more distracted with the iPads in the classrooms. Falc (2013) examined the usage of an e-Textbook in a public speaking class and found that students preferred using a combination of the printed textbook and e-Textbook. The author suggests that instructors could help students by informing them of the drawbacks and showing the students how to use the e-Textbook for maximum effectiveness.

\section{Factors Influencing Use of E-Textbooks}

Many studies have investigated factors that may influence users' usage of e-Textbooks. Morrone and Dennis (2010, Indiana University) investigated e-Textbook usage and four motivational orientations: (1) approach mastery - "I wanted to learn as much as possible", (2) approach performance - "I wanted to get a better grade than others", (3) avoidance performance - "I worried about performing poorly", and (4) avoidance mastery - "I worried that I may not learn all I could". The authors found that those with a high avoidance mastery were more likely to re-read text material. However, those with a high approach mastery had a higher grade than those with lower levels.

Sun, Flores, and Tanguma (2012) explored students' perceptions of e-Books through a survey that measured three factors: (1) e-Book Helpfulness - how much does the book facilitate learning, (2) Learning Outcomes - how much the e-Book helps on the learning outcomes, and (3) Student Involvement - how much does the e-Book promote the student's involvement in learning. The authors found that Student Involvement played a mediating role between e-Book Helpfulness and Learning Outcomes.

Stone and Baker-Eveleth (2013a) explore what motivates students to purchase electronic books through a model and survey. They found that usefulness (helping students succeed in class), ease of use (ease that the student can complete whatever task they desire with the e-Book), and arousal (interest and perceived stimulation students experience with the device) impacted students' likelihood to purchase an e-Book. However, effort (willingness of student to expend effort to find a savings) and value (price and quality combo of the device or book purchase) did not impact likelihood to purchase an e-Book. The authors suggest that instructors should encourage students to use e-Books and emphasize the potential increase in classroom success to increase the usage of e-Books.

An additional study by Stone and Baker-Eveleth (2013b) explored students' intentions to continue to use e-Textbooks through a proposed model and survey. They found that usefulness and satisfaction was related to the intent to continue to use e-Textbooks. The authors suggest monitoring satisfaction with currently chosen e-Textbooks and selecting future e-Textbooks that will engage students in and out of the classroom so that students will find the e-Textbooks useful.

These studies discuss how students use e-Textbooks and the tasks they perform with the e-Textbooks, but they do not explore reasons why they use the e-Textbooks and if they will continue to use the e-Textbooks. Many students have complained about the e-Textbook technology (Jardina et 
al, 2016), so it would be interesting to know if these students would switch back to paper books or continue using a technology they consider unsatisfactory.

\section{Existing Technology Models}

Some models already exist to explain the factors that influence whether students and instructors adopt new technologies, such as the Technology Acceptance Model (TAM) and the Task-Technology Fit (TTF). TAM is a model for user acceptance of a new technology that demonstrates how usefulness and ease of use directly impact a user's attitude toward using the technology. The basic TAM has been updated and extended many times as it has been applied to more new technologies and systems. Venkatesh and Davis (2000) explored an extension of the TAM by trying to explain perceived usefulness and intention to use with social and cognitive influences, also referred to as External Variables. External Variables consisted of Voluntariness, Experience, Subjective Norm, Image, Job Relevance, Output Quality, and Result Demonstrability. They collected data in four organizations, at two organizations the technology was voluntary and at the other two the technology was required. They found that Subjective Norm had a direct effect on Behavioral Intention to Use for mandatory, but not voluntary systems. Subjective Norm is a perception where the user will use or not use a system based on the opinions and habits of the people that are important to the user. This finding is interesting because it may suggest that if instructors require their students to use e-Textbooks, as opposed to regular paper textbooks, the students may be more likely to have an intention to use the e-Textbooks.

Lai and Chang (2011) extended the TAM and found that convenience, compatibility, and media richness were factors in determining a reader's acceptance of e-Book readers. Compatibility, which is how close a user thinks the e-Book experience is related to a paper book experience, was found to be the most influential factor in determining a user's acceptance of e-Book readers. Convenience was found to be a critical factor in e-Book reader usage, as people who want to save time and effort would like the added benefit of e-Book readers allowing them to carry multiple books at once. Finally, Media Richness is another factor that influences intention to use. Media Richness includes multimedia effects such as dynamic displays and content and hyperlinks.

Torres, Johnson, and Imhonde (2014) added perceived playfulness, hedonic and utilitarian content availability constructs to TAM. They found that ease of use is mediated by perceived usefulness and playfulness, and that the type of content in the book is a determining factor in e-Reader usage. Since the content of the book impacts the usage of the technology, it is important to test this with e-Textbooks.

Aharony (2014) found that perceived usefulness, perceived ease of use, personal innovativeness, and other personal characteristics can predict intention to use e-Books among information technology professionals.

Lee (2013) investigated the likelihood to adopt e-Books through a survey method using items from the TAM, Diffusion of Innovation Theory, and the Model of Innovation Resistance. Diffusion of Innovation Theory describes how a person perceives an innovation's attributes, such as advantages of the technology, the compatibility of the technology to the task, complexity of the technology, and the willingness to try the technology, and whether or not the user would adopt the innovation. The Model of Innovation Resistance describes users who do not adopt or resist technology advances.

Lee (2013) found that Innovativeness had an influence on perceived ease of use suggesting that people who are more innovative had more confidence using new technology and therefore thought it was easier to use. Furthermore, Lee (2013) found that perceived usefulness and ease of use had an effect on intention to use and innovation resistance. If users' thought it was useful and easy to use they would be more likely to start using the technology. Innovation Resistance was negatively related to intention to use. Perceived risk was positively related to innovation resistance. The more risk the user thought was involved with the technology the less likely they were to use it. This study was limited because it did not explore reasons people are resistant to e-Books, their internal motivations of usage, and perceived costs. Furthermore, this study did not query students, but rather a general population. 
While the studies with TAM that focused on e-Book and e-Reader usage discovered a great deal about users' intention to use a technology, many questions still remain. For instance, it is important to know how users are actually performing tasks with the technology. It is also important to think about how the task itself fits the particular technology. Another framework, the Task-Technology Fit, can help us understand e-Textbook usage, and is explained in detail in the next section.

\section{Task-Technology Fit and E-Textbook Model}

Task-Technology Fit (TTF) is a framework that suggests that the "fit" between a task and technology that is being used to accomplish the task influences performance and acceptance (Goodhue \& Thompson, 1995). This model has been applied to a variety of technologies in the education domain including: learning management systems (LMS) (McGill, Klobas, \& Renzi, 2011) and digital video tools (Raven, Leeds, \& Park, 2010). These studies demonstrate that the more appropriate the technology is for the users' skills and tasks, the better the performance.

Dishaw and Strong's (1999) study on multiple software applications over several environments resulted in an integrated model that adds TTF constructs and items to the TAM. The TAM explores attitudes of usage while the TTF focuses on the match between task needs and functionality. They found that Task Characteristics have a stronger impact on TTF than TTF has on Perceived Ease of Use (from TAM). Extending TTF with TAM provides a better explanation for variance in technology usage than the models do by themselves.

D'Ambra, Wilson, and Akler (2013) applied the TTF framework to e-Book usage among higher education business and information technology instructors. Results from an exploratory factor analysis to develop a TTF construct specifically for e-Books, revealed three factors that were influential to e-Book usage: (1) Annotation (the ability to bookmark, make notes, and highlight text), (2) Navigation (involves the ability to browse the text using page turning, table of contents, indices, and search), and (3) Output (involves the availability of audio support, high resolution images, and alternative language translation). It was expected that when an e-Book interface provides a positive 'fit' to user expectations for reading tasks, it would be rated as easy to use and satisfying.

In the Wilson, D'Ambra, and Drummond (2014) study, the researchers explored e-Book usage among medical instructors with the same TTF framework as the D'Ambra et al (2013) study, and found similar results. However, neither the D'Ambra et al (2013) nor the Wilson et al (2014) study examined student usage. It is possible that students and instructors would use e-Textbooks very differently from one another.

Gerhart, Peak, and Prybutok (2015), added the Consumer Acceptance and Use of Technology (UTAUT2) to the TTF framework, and tested it specifically to e-Textbook usage with students. The researchers found that if students thought the e-Textbook fit their needs that it positively correlated with their e-Textbook usage and class performance. Furthermore, the four factors that influenced a student's TTF were: (1) substitution (perceiving traditional books and e-Textbooks as similar tools for the same task), (2) habit (forming the habits that are necessary to use the device for the task), (3) hedonic motivation (enjoyment experienced from the technology), and (4) facilitating conditions (aiding the user with the ability to access the e-Textbook).

The Gerhart et al (2015) and the D'Ambra et al (2013) studies use a TTF framework, but have several different latent variables. The Gerhart et al (2015) study added Price Value, Substitutes, Habit, and Hedonic Motivation, which is not seen in the D'Ambra et al (2013) study's TTF model. The D'Ambra et al (2013) study included Task and Individual where the Gerhart et al (2015) study did not. The studies have a few latent variables in common, such as Performance, Utilization, and Technology (called Facilitating Conditions in the Gerhart et al (2015) study). It is interesting to note that both studies followed a similar framework, but developed models mixed with similar and dissimilar elements. 
Table 1. Summary of past research

\begin{tabular}{|c|c|c|c|c|}
\hline $\begin{array}{l}\text { Study } \\
\text { Reference }\end{array}$ & $\begin{array}{l}\text { Model } \\
\text { Tested }\end{array}$ & Technology & Population & Findings \\
\hline Davis, 1986 & TAM & $\begin{array}{l}\text { Word } \\
\text { Processer }\end{array}$ & Students & $\begin{array}{l}\text { In the original TAM study they found that having the } \\
\text { ability to measure a user's attitude toward using a } \\
\text { technology may assist in the development process of a } \\
\text { new technology. }\end{array}$ \\
\hline $\begin{array}{l}\text { Venkatesh \& } \\
\text { Davis, } 2000\end{array}$ & TAM & $\begin{array}{l}\text { Various } \\
\text { Software }\end{array}$ & $\begin{array}{l}\text { General } \\
\text { Population }\end{array}$ & $\begin{array}{l}\text { This study extended the TAM and found that the user's } \\
\text { perception of what they think an important person's } \\
\text { feelings about a technology will influence the user's } \\
\text { usage. }\end{array}$ \\
\hline $\begin{array}{l}\text { Torres, } \\
\text { Johnson, \& } \\
\text { Imhonde, } 2014\end{array}$ & TAM & e-Reader & $\begin{array}{l}\text { General } \\
\text { Population }\end{array}$ & $\begin{array}{l}\text { In this TAM extension the researchers found that } \\
\text { ease of use is mediated by perceived usefulness and } \\
\text { playfulness, and the type of content in the book is a } \\
\text { determining factor in e-Reader usage. }\end{array}$ \\
\hline Aharony, 2014 & TAM & e-Book & IT Pros & $\begin{array}{l}\text { This study extended the TAM and found that } \\
\text { perceived usefulness, perceived ease of use, personal } \\
\text { innovativeness, and other personal characteristics can } \\
\text { predict intention to use. }\end{array}$ \\
\hline Lee, 2013 & TAM & e-Book & $\begin{array}{l}\text { General } \\
\text { Population }\end{array}$ & $\begin{array}{l}\text { This TAM extension found that perceived usefulness } \\
\text { and ease of use have an effect on intention to use and } \\
\text { innovation resistance. }\end{array}$ \\
\hline $\begin{array}{l}\text { Goodhue \& } \\
\text { Thompson, } \\
1995\end{array}$ & TTF & $\begin{array}{l}\text { Various } \\
\text { Software }\end{array}$ & $\begin{array}{l}\text { General } \\
\text { Population }\end{array}$ & $\begin{array}{l}\text { This is the original TTF work, which shows that the } \\
\text { more appropriate the technology is for the users' skills } \\
\text { and tasks, the better the performance. }\end{array}$ \\
\hline $\begin{array}{l}\text { Dishaw \& } \\
\text { Strong, } 1999\end{array}$ & $\begin{array}{l}\text { TTF \& } \\
\text { TAM }\end{array}$ & $\begin{array}{l}\text { Various } \\
\text { Software }\end{array}$ & $\begin{array}{l}\text { General } \\
\text { Population }\end{array}$ & $\begin{array}{l}\text { Combined the TAM and the Task-Technology Fit (TTF) } \\
\text { and their study resulted in an integrated model that adds } \\
\text { TTF constructs/items to the TAM. }\end{array}$ \\
\hline $\begin{array}{l}\text { D'Ambra, } \\
\text { Wilson, \& } \\
\text { Akler, } 2013\end{array}$ & TTF & e-Book & Instructor & $\begin{array}{l}\text { This is a TTF extension that revealed three main factors } \\
\text { that were influential to e-Book usage: Annotation, } \\
\text { Navigation, and Output. }\end{array}$ \\
\hline $\begin{array}{l}\text { Wilson, } \\
\text { D'Ambra, \& } \\
\text { Drummond, } \\
2014\end{array}$ & TTF & e-Book & Instructor & $\begin{array}{l}\text { This study further explored the TTF with e-Book } \\
\text { adoption among business and information technology } \\
\text { instructors. }\end{array}$ \\
\hline $\begin{array}{l}\text { Gerhart, Peak, } \\
\& \text { Prybutok, } \\
2015\end{array}$ & TTF & e-Text book & Student & $\begin{array}{l}\text { Further exploration of TTF and found that four main } \\
\text { factors of usage were: (1) substitution, (2) habit, ( } 3 \text { ) } \\
\text { hedonic motivation, and (4) facilitating conditions. }\end{array}$ \\
\hline $\begin{array}{l}\text { Jardina, Gillett, } \\
\text { \& Chaparro, } \\
2016\end{array}$ & None & e-Text book & Student & $\begin{array}{l}\text { Students feel limited by e-Textbooks due to access } \\
\text { issues, (e.g., reliance on battery life and Internet } \\
\text { access) and many were frustrated that interactions with } \\
\text { e-Textbooks were difficult or tasks were impossible to } \\
\text { complete. }\end{array}$ \\
\hline
\end{tabular}

A summary of the research so far is shown in Table 1. The summary includes which model was being tested, the type of software or device involved in the study, the population tested, and the study's findings.

\section{RESEARCH MODEL AND HYPOTHESIS}

Recently, a survey on e-Textbook usage was conducted that revealed additional reasons as to why users may struggle with e-Textbook usage (Jardina et al, 2016). Results indicate that students feel 
limited by e-Textbooks due to a hindrance or unreliability in technical access, such as a reliance on battery life and internet access. Furthermore, many participants expressed frustration with awkward interactions with e-Textbooks that prevented them or made it difficult to complete tasks (e.g., highlighting, annotating, bookmarking, etc.) that would be easier in a paper textbook.

While the Gerhart et al (2015) study offers the most complete e-Textbook usage model, it has only been tested with students. We do not know if the model will have a similar fit, if used with instructors. Instructors use e-Textbook differently, may have different motivations to utilize the technology, and do not need to consider price when choosing an e-Textbook. This means certain constructs in the Gerhart et al (2015) model may weigh heavier or differently for students than instructors. In addition, a previous study using the TTF (D'Ambra et al, 2013) with instructors found relationships among different latent variables than the Gerhart et al (2015) study. This means that not only did the D'Ambra et al (2013) and Gerhart et al (2015) study differ with user group, they also differed on factors making it impossible to collapse across the studies and compare differences in students and instructors. It is important to see how similar or different students and instructors are, so that e-Textbook developers know their audience better.

Due to the limitations of the models (D'Ambra et al, 2013; Gerhart et al, 2015), and the results of the e-Textbook survey (Jardina et al, 2016) a new model was developed for e-Textbook usage and tested among students and instructors.

The purpose of this study is to develop a new model based on TTF and test it with both students and instructors, which has not been done before. The new model builds four constructs from D'Ambra et al (2013), Gerhart et al, 2015, Torres et al, 2014, and Jardina et al., 2016 and adds Perceived Ease of Use based on. The four constructs are: Task-Technology Fit, Performance, Access, and Perceived Ease of Use. More details about the constructs and the items that represent each construct are available in Table 2.

The four constructs and previous research was used to hypothesize the relationships between the latent variables so that the model could be tested to determine if there was a fit for e-Textbook usage among students and instructors. The proposed e-Textbook usage model is shown in Figure 1

Many studies on e-Textbook and e-Book usage have found that Technology, which encompasses the functionality a user would like on their e-Books and the access the user has to the e-Book, positively impacted TTF (D'Ambra et al, 2013; Gerhart et al, 2015; Lai \& Chang, 2011). The Gerhart et al (2015) study found that Facilitating Conditions, which has to do with access to the technology, was positively related to TTF among students. Lai and Chang (2011) found that Convenience, which means how easy it was to access the technology, was positively related to technology acceptance. Our proposed model combined Facilitating Conditions and Convenience elements to define Access to technology. Access determines if the user is given all the necessary features and capabilities to access the e-Textbook.

H1: Access will positively impact TTF for e-Textbook usage among students and instructors.

The D'Ambra et al (2013) study found that TTF positively impacted Performance in e-Textbook usage among instructors, and Gerhart et al (2015) found that TTF positively impacted Expected Performance among students. How users perform on a task can impact a user's usage of a technology, therefore it is hypothesized that Performance will be related to TTF in e-Textbooks for both instructors and students. For instance, if the user thinks the task can be accomplished with the e-Textbook (a high TTF) then they are likely to perform better with the e-Textbooks. However, instructors might use a lot of tools for teaching (e.g. Blackboard, PowerPoint, etc.), so the impact an e-Textbook has on an instructor's overall Performance may be less than for a student. Students get the majority of their class materials from an e-Textbook, and do not usually have to delve too deeply into the various functions of other technologies (e.g. Blackboard, PowerPoint, etc.) to the extent that an instructor would. Therefore, the impact of TTF on Performance will be stronger for students than instructors. 


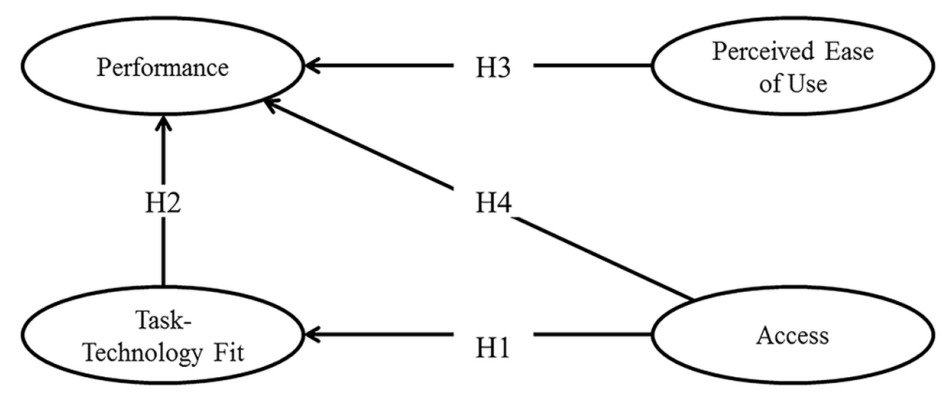

H2: TTF will positively impact Performance in e-Textbooks among students and instructors.

Many studies have found that Ease of Use is related to usage or intention to use the technology (Lee, 2013; Torres, Johnson, \& Imhonde, 2014; Venkatesh \& Davis, 2000) or/and how useful a user believes the technology to be (Goodhue \& Thompson, 1995; Lee, 2013; Torres et al, 2014; Venkatesh $\&$ Davis, 2000). The easier a user thinks an e-Textbook is to use, the more likely they are to use it and the better their performance.

H3: A User's Perceived Ease of Use will have a positive impact on a user's Performance among students and instructors.

Previous research has found that TTF is a mediator for Performance and Technology Access. The Gerhart et al (2015) study found that TTF mediated Facilitating Conditions and Expected Performance, and the D'Ambra et al (2013) study found that TTF mediated Technology and Performance. However, the current study has added newly proposed items to extend the Access latent variable based off of previous research. It is hypothesized that this change will directly relate Access and Performance to one another, since a user needs to have access to certain technological capabilities to be able to fully perform with an e-Textbook. For instance, if a user does not feel they have the necessary resources or cannot access their e-Textbook from multiple devices, they may feel they perform poorly within an e-Textbook.

H4: Access will positively impact Performance for e-Textbook usage among students and instructors.

\section{METHODOLOGY}

To test the newly proposed model, we conducted a survey of students and instructors at institutions of higher education about their usage of e-Textbooks.

\section{Demographics}

A total of 708 participants filled out the survey. Respondents who did not complete the survey (n $=65)$ or who indicated that they had never attended an institution of higher education $(n=55)$ or never used an e-Textbook $(n=66)$ were all eliminated for a final participant total of 524. Of these participants, 423 were students and 99 were instructors. There were 221 males (Students = 177; Instructor $=44$ ) and 303 females (Students $=247$; Instructor $=56$ ). The average age was 32 (Students $=28$; Instructors $=48$ ) with the youngest being 18 and the oldest being 74 . 
Participants were from a range of universities, majors, and departments. They were recruited through various outlets and asked to fill out the survey via the software program Qualtrics. Participants were compensated with course credit or entered into drawings to win one of twenty \$25 Amazon gift cards.

\section{Measures}

The current study aims to broaden the population of the existing e-Textbook usage models by investigating the usage of e-Textbooks by both students and instructors. The new model combines four constructs from D'Ambra et al (2013), Gerhart et al, 2015, Torres et al, 2014, and Jardina et al, 2016. They are: Task-Technology Fit, Performance, Access to technology, and Perceived Ease of Use. The definitions of the constructs, the items that represent each construct, and the source of each item are available in Table 2.

Overall, the items between students and instructors were the same, but some of the original items were changed to make them more relevant to e-Textbook usage and to both audiences. For instance, the D'Ambra et al (2013) item "I use e-books for researching a topic" was changed to "I use e-Textbooks for researching a topic" All items are on a 7-point Likert scale (1 - strongly disagree; 7 - strongly agree). Some items also were different depending on if the participant was an instructor or student. For example, students would see "E-Textbooks help me to improve the quality of my learning", but instructors would see "E-Textbooks help me to improve the quality of my teaching".

\section{ANALYSIS AND RESULTS}

Microsoft Excel 2013, IBM SPSS Statistics version 22, and SPSS AMOS version 22 were used to analyze the data. An exploratory factor analysis was conducted to determine the factors for the newly proposed e-Textbook Usage Model. Following that, a structural equation model was performed and the hypotheses were tested.

\section{Normality}

To test the normality of the collected data set, the Shapiro-Wilk test was used as a numerical representation and the Normal Q-Q Plots were used as a graphical representation. A visual assessment of the Normal Q-Q Plots showed that most items were negatively skewed. The Shapiro-Wilk test was chosen because it is appropriate for the sample size of this study $(N=524)$, as the Shapiro-Wilk test can handle a wide range of sample sizes from 50 to 2000 (Lund \& Lund, 2013). The data is considered normal when the significance of the Shapiro-Wilk test is above 0.05 . The results of the Shapiro-Wilk test determined that the data in this sample was not normal.

According to Bulmer (1979), a highly skewed sample is less than -1.00 or greater than +1.00 , a moderately skewed sample is between -1.00 and -0.50 or between +1.00 and +0.50 , and an approximately symmetric sample is between -0.50 and +0.50 . A majority of the items had a negatively skewed distribution, and most of the items were considered moderately skewed, as the values fell between -1.00 and -0.50 or between +1.00 and +0.50 .

Several researchers have indicated that factor analyses are conducted on highly skewed data (Muthen \& Kaplan, 1985; Wang, Fan, \& Willson, 1996), and data transformations are not always desirable when the responses are skewed (Norris \& Aroian, 2004). In fact, Norris and Aroian (2004) found that Cronbach's alpha and Pearson product-moment correlations were no different between original and the transformed data. Therefore, the moderately skewed data in this study was not transformed. 
Access - The technology access the user possesses to access all the necessary features and capabilities within the e-Textbook.

- I have the hardware necessary to use e-Textbooks (Gerhart, 2015)

- I have the software necessary to use e-Textbooks (Gerhart, 2015)

- I have the resources necessary to use e-Textbooks. (Resources includes everything you would need to access an e-Textbook: appropriate software, hardware, wifi, etc.) (Gerhart, 2015)

- I can access e-Textbooks from multiple devices (New)

- I can access multiple e-Textbooks at the same time (New)

- I can access the e-Textbook offline (New)

TTF - The types of tasks that a user wants to accomplish within an e-Textbook. Within an e-Textbook, I would like to be able to:

- Annotate: Bookmark, Annotate, Highlight (D’Ambra, 2013)

- Navigation: Browse table of contents, Browse the index, Link from indices to text, Search across full text (D'Ambra, 2013)

- Output: Copy, Have a read-aloud option, View high resolution images, Translate to other language, Print (D’Ambra, 2013)

- Collaboration: Share notes and highlights, View shared notes and highlights of instructor, View shared notes and highlights of fellow classmates (New)

- Multimedia: View embedded video, Interact with multimedia material, Take quizzes/self-assessment (New)

- Appearance: Adjust text color, Adjust contrast, Change font size (New)

Perceived Ease of Use - The ease that a user can accomplish a task with an e-Textbook. Rate the difficulty of the following features with an e-Textbook:

- Annotation features (bookmark, highlights, and notes) (New)

- Output features (Copy, print, and read-aloud option) (New)

- Navigation features (table of contents, index, search) (New)

- Collaboration features (viewing/sharing notes and highlights) (New)

- Multimedia features (take quizzes/self-assessments, view videos) (New)

- Appearance features (change font size and color, adjust contrast) (New)

Performance - The capability of the e-Textbook to help the user accomplish tasks well. E-Textbooks help me to improve the quality of my learning/teaching D'Ambra (2013)

- E-Textbooks help me to improve the quality of my research (D’Ambra, 2013)

- E-Textbooks improve my productivity (D’Ambra, 2013)

- E-Textbooks help me to accomplish more work than would otherwise be possible (D'Ambra, 2013)

- E-Textbooks help me to perform in my classes/job better (D'Ambra, 2013)

\section{Missing Data}

Less than $1 \%$ of the total data from the 54 -items was missing. Such a low percentage of missing data has been considered as negligible by previous researchers (Bennett, 2001; Peng, Harwell, Liou, \& Ehman, 2006; Schafer, 1999).

A Little's MCAR test was conducted to determine if the missing data was missing completely at random or not. The results of the Little's MCAR test $\left(x^{2}(48, N=524)=90.52, p<.05\right)$ suggested that the data was not missing completely at random. (NOTE: a p-value of more than 0.05 is needed to assume that the values are missing completely at random.) However, only $11 \%$ (6 of 54) of the items were missing any data. The items that were missing data were only missing data on $2 \%$ of the cases, which means none of the variables were removed at this stage in the analysis process.

\section{Factorability}

Tabachnick and Fidell (2007) suggest that it is a good idea to have at least 300 cases for a factor analysis. Additionally, Comrey and Lee (1992) provide a sample size classification rating, which rates this study's sample size $(N=524)$ as "very good". (NOTE: the following contains Comrey and Lee's (1992) classification and rating of sample sizes: 50 is "very poor", 100 is "poor", 200 is "fair", 300 is "good", 500 is "very good", and 1000 is "excellent".) 
Furthermore, the correlations between items were examined to ensure the suitability of using a factor analysis. Tabachnick and Fidell (2007) suggest that several of the items should have intercorrelations above 0.30 , or a factor analysis is not suitable for analysis. The correlation matrix showed several intercorrelations above 0.30 and were therefore deemed appropriate for factor analysis.

Tabachnick and Fidell (2007) suggest two tests to examine the sphericity of data for a factor analysis: the Kaiser-Meyer-Olkin (KMO) and Bartlett's test of sphericity. The KMO value is considered stronger as it approaches 1 , and a value of at least 0.60 is needed to assume sphericity. The KMO value for the sample in this study is 0.92 , which means the KMO determined the data has sphericity. Furthermore, the Bartlett's test of sphericity was significant, $x^{2}(1431)=17,931.18, p<$ 0.01 , indicating sphericity.

Due to the large sample size, the intercorrelations of the variables, and sphericity of the data a factor analysis is appropriate with the given data (Tabachnick \& Fidell, 2007).

\section{Factor Extraction}

Since the data in this study was not normally distributed as determined by the Shapiro-Wilk test and the Normal Q-Q Plots, PAF was used as the extraction method (Costello \& Osborne, 2005; Fabrigar, Wenener, MacCallum, \& Strahan, 1999). The rotation method used was an oblique rotation, specifically the promax rotation (kappa $=4$ ). The inter-factor correlations were above 0.30 , which provided grounds to use the oblique rotation (Tabachnick \& Fidell, 2007).

Multiple strategies were implemented to determine the number of factors to keep, such as the Kaiser-Guttman criterion and the Cattell's scree plot test. Based on the Kaiser-Guttman criterion there were 11 factors to keep; however, the scree plot results show that the upper-bound of the number of factors was 4 with the eigenvalue greater than 1 criteria. (Detailed scree plot results are shown in Appendix H). Many researchers suggest that factors with less than three items are unstable, and should be rejected (Costello \& Osborne, 2005; Hinkin, 1995; Russell, 2002). Additionally, factors need to have a simple structure and be easy to explain; consequently, factors that were difficult to interpret were not retained.

To interpret the factors, the pattern and structure matrices were examined, but the pattern matrix was the focus because it provides the clearest results (Costello \& Osborne, 2005; Field, 2007; Tabachnick \& Fidel, 2007). 0.40 was the cutoff value for the item loadings because it is the most common value recommended for the cutoff range (Field, 2009; Tabacnhick \& Fidell, 2007).

Based on the factor extraction criteria mentioned, a 4-factor solution was decided. The four factors accounted for $48.71 \%$ of the total variance, and the Cronbach's alpha for each item and the latent variable surpassed the 0.70 acceptable threshold (see tables 4-7).

\section{Factor Model}

Each factor was named based on the five highest pattern matrix loadings. The four factors were named: Performance, Task-Technology Fit, Perceived Ease of Use, and Access. The Performance factor accounted for $25.34 \%$ of the item variance, TTF accounted for $11.97 \%$ of the item variance, Access accounted for $5.92 \%$ of the item variance, and Perceived Ease of Use accounted for $5.49 \%$ of the item variance. $48.71 \%$ of the total variance was accounted for by these 4 factors. Table 3 display the items from each of the four factors, along with each item's mean, standard deviation, pattern and structure matrices loading values, the communality coefficient $\left(h^{2}\right)$, and Cronbach's Alpha. These four factors were the basis for the model developed from the data.

Pearson's correlations tests were conducted to assess the relationship among the four factors. There is a significant positive relationship between all the factors. Table 4 displays the correlation matrix between the factors. 
Table 3. Summary Statistics of Factor Items' Loadings

\begin{tabular}{|c|c|c|c|c|c|c|c|}
\hline \multirow{2}{*}{ Factor } & \multirow{2}{*}{ Item } & \multirow{2}{*}{ Mean } & \multirow{2}{*}{ SD } & \multicolumn{2}{|c|}{ Factor Loadings } & \multirow{2}{*}{$h^{2}$} & \multirow{2}{*}{$\begin{array}{l}\text { Cronbach's } \\
\text { Alpha }\end{array}$} \\
\hline & & & & Pattern & Structure & & \\
\hline \multirow{5}{*}{ Performance } & $\begin{array}{l}\text { E-Textbooks help me to improve the } \\
\text { quality of my learning/ teaching }\end{array}$ & 3.96 & 1.888 & 0.882 & 0.848 & 0.733 & 0.930 \\
\hline & $\begin{array}{l}\text { E-Textbooks help me to improve the } \\
\text { quality of my research }\end{array}$ & 3.85 & 1.941 & 0.868 & 0.841 & 0.718 & 0.930 \\
\hline & $\begin{array}{l}\text { E-Textbooks help me to perform } \\
\text { better in my classes/job }\end{array}$ & 3.96 & 1.883 & 0.864 & 0.841 & 0.717 & 0.930 \\
\hline & $\begin{array}{l}\text { E-Textbooks help me to accomplish } \\
\text { more work than would otherwise be } \\
\text { possible }\end{array}$ & 3.89 & 1.969 & 0.859 & 0.839 & 0.698 & 0.930 \\
\hline & $\begin{array}{l}\text { E-Textbooks improve my } \\
\text { productivity }\end{array}$ & 4.10 & 1.922 & 0.837 & 0.828 & 0.709 & 0.930 \\
\hline \multirow{5}{*}{ TTF } & Annotate - Bookmark & 6.23 & 1.304 & 0.696 & 0.750 & 0.602 & 0.931 \\
\hline & Multimedia - View embedded video & 5.93 & 1.465 & 0.734 & 0.737 & 0.546 & 0.931 \\
\hline & $\begin{array}{l}\text { Output - View high resolution } \\
\text { images }\end{array}$ & 5.89 & 1.457 & 0.729 & 0.727 & 0.530 & 0.931 \\
\hline & $\begin{array}{l}\text { Multimedia - Interact with } \\
\text { multimedia material }\end{array}$ & 5.78 & 1.547 & 0.719 & 0.723 & 0.527 & 0.931 \\
\hline & $\begin{array}{l}\text { Navigation - Browse table of } \\
\text { contents }\end{array}$ & 6.26 & 1.241 & 0.624 & 0.718 & 0.619 & 0.931 \\
\hline \multirow{5}{*}{ Access } & $\begin{array}{l}\text { I have the hardware necessary to use } \\
\text { e-Textbooks }\end{array}$ & 6.26 & 1.227 & 0.838 & 0.807 & 0.664 & 0.932 \\
\hline & $\begin{array}{l}\text { I have the software necessary to use } \\
\text { e-Textbooks }\end{array}$ & 6.20 & 1.284 & 0.831 & 0.808 & 0.664 & 0.932 \\
\hline & $\begin{array}{l}\text { I have the resources necessary to use } \\
\text { e-Textbooks. (Resources includes } \\
\text { everything you would need to access } \\
\text { an e-Textbook: appropriate software, } \\
\text { hardware, wifi, etc.) }\end{array}$ & 6.25 & 1.213 & 0.849 & 0.826 & 0.688 & 0.932 \\
\hline & $\begin{array}{l}\text { I can access the same e-Textbook } \\
\text { from multiple devices. }\end{array}$ & 5.97 & 1.526 & 0.592 & 0.655 & 0.450 & 0.931 \\
\hline & $\begin{array}{l}\text { I can access multiple e-Textbooks at } \\
\text { the same time }\end{array}$ & 5.20 & 1.919 & 0.472 & 0.519 & 0.308 & 0.932 \\
\hline \multirow{5}{*}{ Perceived Ease of Use } & $\begin{array}{l}\text { Collaboration features (viewing/ } \\
\text { sharing notes and highlights) }\end{array}$ & 4.96 & 2.276 & 0.848 & 0.803 & 0.661 & 0.933 \\
\hline & $\begin{array}{l}\text { Output features (copy, print, and } \\
\text { read-aloud option) }\end{array}$ & 5.00 & 2.104 & 0.807 & 0.781 & 0.619 & 0.932 \\
\hline & $\begin{array}{l}\text { Annotation features (bookmark, } \\
\text { highlights, and notes) }\end{array}$ & 5.31 & 1.869 & 0.774 & 0.774 & 0.610 & 0.932 \\
\hline & $\begin{array}{l}\text { Appearance features (change font } \\
\text { size and color, adjust contrast) }\end{array}$ & 5.50 & 1.838 & 0.751 & 0.761 & 0.557 & 0.932 \\
\hline & $\begin{array}{l}\text { Multimedia features (take quizzes/ } \\
\text { self-assessments, view videos) }\end{array}$ & 5.26 & 1.967 & 0.766 & 0.743 & 0.588 & 0.932 \\
\hline
\end{tabular}

Furthermore, a separate factor analysis was also conducted on the TTF measured variables to see if they fit into the predetermined groups (Navigation, Output, Collaboration, Appearance, Multimedia, and Annotate). The results suggest that there are four groups, instead of six. The four groups are Navigation and Annotation, Appearance and Multimedia, Collaboration, and Output. These findings are different from the D'Ambra et al (2013) study, as that study only had three groups (Navigation, Annotation, and Output); however, the current study added several more features. 
Table 4. Factor component correlation matrix

\begin{tabular}{|l|l|l|l|l|}
\hline Factors & Performance & TTF & Access & PEOU \\
\hline Performance & 1.000 & -- & -- & -- \\
\hline TTF & 0.301 & 1.000 & -- & -- \\
\hline Access & 0.271 & 0.321 & 1.000 & -- \\
\hline PEOU & 0.300 & 0.211 & 0.244 & 1.000 \\
\hline
\end{tabular}

\section{Structural Equation Model and Hypothesis Results}

A structural equation model (SEM) analysis was performed based on the e-Textbook usage survey data from college students and instructors on the four latent variables (Access, TTF, Performance, and Perceived Ease of Use). The results from the SEM analysis are presented in Figure 2. In the figure, circles represent latent variables, rectangles represent measured variables, and connecting lines represent hypothesized direct effects.

Figure 2. SEM of e-Textbook Model

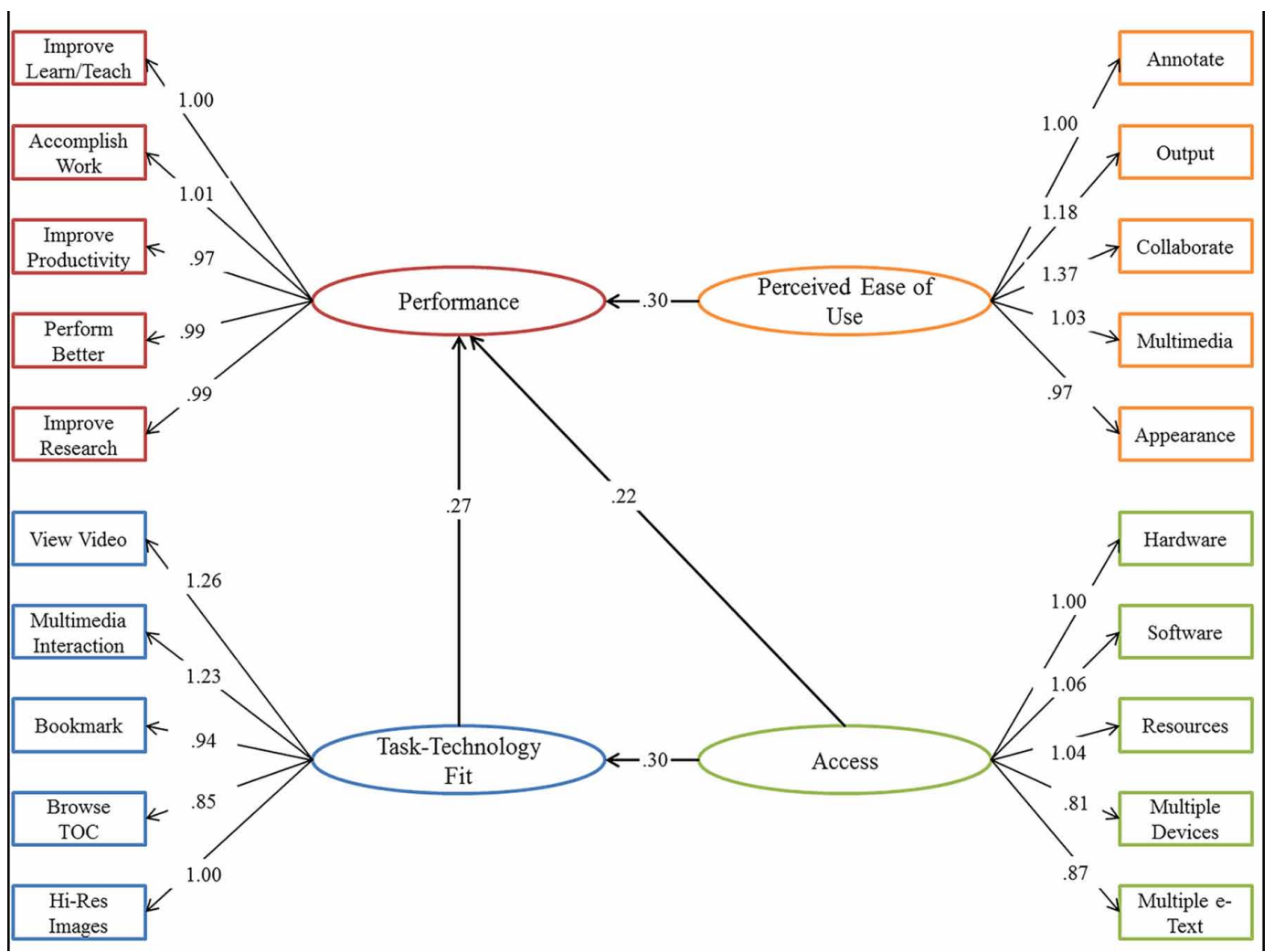

The hypothesized model was tested and support was found for the hypothesized model, $x^{2}(166$, $N=524)=629.50, p<0.01$, comparative fit index $(\mathrm{CFI})=0.93$, root mean square error of approximation $(\mathrm{RMSEA})=0.07$. The CFI ranges from zero to 1.00 and a 0.90 value or greater is 
considered representative of a model that effectively describes the data. It is recommended that the RMSEA value be anywhere between 0.05 and 0.08 to indicate a well-fitting model (Byrne, 2010).

Table 5 shows the significance of each hypothesis and the standardized regression weights for the correlations between the latent variables. The e-Textbook usage model based off the factor analysis is a significant, strong fit.

\section{Table 5. Hypothesis Results}

\begin{tabular}{|l|l|l|l|}
\hline Latent Variable & Direction & $\begin{array}{l}\text { Latent } \\
\text { Variable }\end{array}$ & $\begin{array}{l}\text { Standardized } \\
\text { Regression } \\
\text { Weights }\end{array}$ \\
\hline TTF & & Access & $0.32^{*}$ \\
\hline Performance & & TTF & $0.15^{*}$ \\
\hline Performance & & Access & $0.13^{*}$ \\
\hline Performance & PEOU & $0.22^{*}$ \\
\hline *Indicates significance at the $p<0.01$ level. & & \\
\hline
\end{tabular}

\section{Hypothesis 1}

The hypothesis that Access would positively impact TTF for e-Textbook usage among students and instructors (Hypothesis 1) was confirmed. This finding is in line with previous studies which found that access positively impacted TTF (D'Ambra et al, 2013; Gerhart et al, 2015; \& Lai \& Chang, 2011). The finding is not surprising, as it shows that users need to have the appropriate resources, hardware, and software to feel that the e-Textbook is a good fit for the tasks they would like to complete with it.

\section{Hypothesis 2}

The hypothesis that TTF would positively impact Performance with e-Textbooks (Hypothesis 2) was confirmed. It makes sense that how one performs with a device would impact what they would like to do with the device (TTF). For instance, if a user thinks their performance has improved with e-Textbook usage, they may expect the device to do more for them than others who did not feel their performance improved.

\section{Hypothesis 3}

Perceived Ease of Use positively impacted e-Textbook Performance (Hypothesis 3). This is in line with previous studies, which have found that people believe they perform better when they perceive something as easier to use. Also, many other TTF and TAM models have found PEOU to impact latent variables in their models (Dishaw \& Strong, 1999; Lee, 2013; Torres et al, 2014; Venkatesh \& Davis, 2000).

\section{Hypothesis 4}

Access was found to positively impact Performance (Hypothesis 4). It makes sense that students and instructors would need to feel they have full access to the technology in order to feel they are performing well. If a user were to think they could not access important parts of the e-Textbook capabilities they may perceive their performance to suffer.

The results of the hypotheses testing show that the proposed model is a good one to use to explain e-Textbook usage for students and instructors. 


\section{DISCUSSION}

This research investigated a new model to aid in the explanation of e-Textbook usage for students and instructors. This work adds to the body of research on the Technology Acceptance Model and TaskTechnology Fit, and furthers the relatively newer research of e-Textbook usage. The findings show that Access, Performance, Perceived Ease of Use, and TTF are important to students and instructors regarding their e-Textbook usage.

The factor analysis showed that four factors (Performance, TTF, Perceived Ease of Use, and Access) accounted for almost half $(48.71 \%)$ of the variance in the factor analysis. This is similar to other studies, as the D'Ambra et al (2013) study found that its model accounted for 50\% of e-Textbook usage among instructors. However, the model in the current study found similar results with a new latent variable (Perceived Ease of Use), which had not previously been used in a study dealing with e-Textbook usage and the TTF model (D'Ambra et al, 2013; Gerhart et al, 2015). Furthermore, there were several variables in the D'Ambra et al (2013) model that were not in the current study's model.

Two studies that were published after the current study was conducted shed some additional light on e-textbook adoption and continuance of use. Gerhart, Peak and Prybutok (2017) re-examined e-textbook adoption among $300+$ student users and propose a simpler explanatory model of only three constructs perceived usefulness, hedonic motivation, and habit for e-textbook adoption. Interestingly, they eliminated perceived TTF and found perceived ease of use to not significantly contribute to the model. In addition, D'Ambra, Wilson, and Akter (2018), suggest the constructs of perceived quality and perceived value/cost to be important factors contributing to continued use of e-textbooks. Neither study included responses from instructors. Future research is needed to determine whether these discrepancies are due to different student samples and/or changes in attitudes as e-textbooks become less novel and experience increases,

\section{CONCLUSION}

This study yielded practical results to apply to e-Textbook usage among students and instructors. This section will explore the study's limitations, discuss the practical implications, and venues for future research.

While previous studies looked at only a single population (instructors or students), this study examined e-Textbook usage of both audiences. However, a limitation of this study was the small instructor sample size. Instructors were vastly outnumbered by students, and incentivizing students is much easier (e.g., offering class credit or the possibility of a small monetary reward) than instructors. In the future, a study on this topic should look to gain a larger instructor sample size.

The newly supported model developed in this study will provide a foundation for further studies investigating the usage of e-Textbook applications, especially in light of the recent results by Gerhart and colleagues (2017). In addition, e-Textbook developers can use these results as a foundation to demonstrate that usability and Ease of Use is important to users. This will indicate to developers that putting money and effort into usability testing a new e-Textbook application will be a good investment to help improve the users' experience.

Along with having a wider range of participants, it would be interesting to parse out the different e-Textbook applications (e.g., Kindle, Chegg, CourseSmart, Nook Study, etc.) to see if there is one application that rates highest on Perceived Ease of Use. Previous studies have found differences in ease of use or usability between e-Textbook applications and devices (Berg et al, 2010; Jardina \& Chaparro, 2011; Jardina \& Chaparro, 2012; Jardina \& Chaparro, 2013; Jardina \& Chaparro, 2015; Siegenthaler, Wurtz, \& Groner, 2010). If an application rates the highest on Perceived Ease of Use it should also rate high on Performance. The application with the highest rating could be used as an exemplar for other e-Textbook applications. It would be beneficial for users to utilize the easiest to use application, as it may increase their performance. Making e-Textbook applications easier to use would also be beneficial for e-Textbook developers as more students and instructors may purchase their products. 


\section{REFERENCES}

Abdullah, N., \& Gibb, F. (2008). Students' attitudes towards e-books in a Scottish higher education institute: Part 1. Library Review, 57(8), 593-605. doi:10.1108/00242530810899577

Abdullah \& Gibb. (2009). Students' attitudes towards e-books in a Scottish higher education institute: Part 2. Library Review, 57(9).

Bennett, D. A. (2001). How can I deal with missing data in my study? Australian and New Zealand Journal of Public Health, 25(5), 464-469. doi:10.1111/j.1467-842X.2001.tb00294.x PMID:11688629

Berg, S.A., Hoffmann, K., \& Dawson, D. (2010). Not on the Same Page: Undergraduates' Information Retrieval in Electronic and Print Books. Western Libraries Staff Publications. Paper 19.

Berry, T., Cook, L., Hill, N., \& Stevens, K. (2011). An exploratory analysis of textbook usage and study habits: Misperceptions and barriers to success. College Teaching, 59(1), 31-39. doi:10.1080/87567555.2010.509376

Bulmer, M. G. (1979). Principles of statistics. Dover Publications, Inc.

Byrne, B. M. (2013). Structural equation modeling with AMOS: Basic concepts, applications, and programming. Routledge.

Chao, P. Y., \& Chen, G. D. (2009). Augmenting paper-based learning with mobile phones. Interacting with Computers, 21(3), 173-185. doi:10.1016/j.intcom.2009.01.001

Comrey, A. L., \& Lee, H. B. (1992). A first course in factor analysis (2nd ed.). Lawrence Erlbaum Associates.

Costello, A. B., \& Osborne, J. W. (2005). Best practices in exploratory factor analysis: Four recommendations for getting the most from your analysis. Practical Assessment, Research \& Evaluation, 10(7), 1-9.

D'Ambra, J., Wilson, C. S., \& Akter, S. (2013). Application of the task-technology fit model to structure and evaluate the adoption of e-books by academics. Journal of the American Society for Information Science and Technology, 64(1), 48-64. doi:10.1002/asi.22757

D’Ambra, J., Wilson, C. S., \& Akter, S. (2018). Continuance of E-Textbook Use by Tertiary Students: A Qualitative Approach. Journal of Computer Information Systems, 1-10.

Davis, F. D. (1986). A technology acceptance model for empirically testing new end-user information systems: Theory and results (Doctoral dissertation). Massachusetts Institute of Technology.

Dennis. (2011). e-Textbooks at Indiana University: A Summary of Two Years of Research. Indiana University.

Dishaw, M. T., \& Strong, D. M. (1999). Extending the technology acceptance model with task-technology fit constructs. Information \& Management, 36(1), 9-21. doi:10.1016/S0378-7206(98)00101-3

Fabrigar, L. R., Wegener, D. T., MacCallum, R. C., \& Strahan, E. J. (1999). Evaluating the use of exploratory factor analysis in psychological research. Psychological Methods, 4(3), 272-299. doi:10.1037/1082-989X.4.3.272

Falc, E. O. (2013). An assessment of college students' attitudes towards using an online e-textbook. Interdisciplinary Journal of E-Learning and Learning Objects, 9, 1-12.

Gerhart, N., Peak, D., \& Prybutok, V. R. (2017). Encouraging E-Textbook Adoption: Merging Two Models. Decision Sciences Journal of Innovative Education, 15(2), 191-218. doi:10.1111/dsji.12126

Gerhart, N., Peak, D. A., \& Prybutok, V. R. (2015). Searching for New Answers: The Application of TaskTechnology Fit to E-Textbook Usage. Decision Sciences Journal of Innovative Education, 13(1), 91-111. doi:10.1111/dsji.12056

Goodhue, D. L., \& Thompson, R. L. (1995). Task-technology fit and individual performance. Management Information Systems Quarterly, 19(2), 213-236. doi:10.2307/249689

Horney, M. A., \& Anderson-Inman, L. (1994). The electro text project: Hypertext reading patterns of middle school students. Journal of Educational Multimedia and Hypermedia, 3(1), 71-91.

Indiana University Study. (2010). Indiana university e-textbook project spring 2010 findings. Alan Dennis, Thomas Duffy, and Anastasia Morrone, Indiana University e-Textbook Project: Spring 2010 Finding. Indiana University. 
Indiana University Study. (2012). Internet2 e-textbook spring 2012 pilot final project report. Author.

Jardina, J. R., \& Chaparro, B. (2011). Mark that e-page! The usability of making notes, bookmarks, and highlights in three e-readers. Usability News. http://usabilitynews.org/mark-that-e-page-the-usability-of-making-notesbookmarks-and-highlights-in-three-e-readers/

Jardina, J. R., \& Chaparro, B. (2012). Usability of e-readers for book navigation tasks. Proceedings of the 56th Meeting of the Human Factors and Ergonomics Society. doi:10.1177/1071181312561276

Jardina, J. R., \& Chaparro, B. (2013). Usability, engagement, and satisfaction of two e-textbook applications. Proceedings of the Human Factors and Ergonomics Society 57th Annual Meeting. doi:10.1177/1541931213571104

Jardina, J. R., \& Chaparro, B. S. (2015). Investigating the usability of e-textbooks using the technique for human error assessment. Journal of Usability Studies, 10(4), 140-159.

Jardina, J. R., Gillett, C., \& Chaparro, B. (2016). Students' usage of e-textbook applications. Usability News.

Johnson, L., Levine, A., Smith, R., \& Stone, S. (2010). The 2010 Horizon Report. The New Media Consortium.

Lai, J. Y., \& Chang, C. Y. (2011). User attitudes toward dedicated e-book readers for reading: The effects of convenience, compatibility and media richness. Online Information Review, 35(4), 558-580. doi:10.1108/14684521111161936

Lee, H. J., \& Yau, K. A. (2015). Addressing the major information technology challenges of electronic textbooks. Journal of Computer Information Systems, 55(2), 40-47. doi:10.1080/08874417.2015.11645755

Lee, S. (2013). An integrated adoption model for e-books in a mobile environment: Evidence from South Korea. Telematics and Informatics, 30(2), 165-176. doi:10.1016/j.tele.2012.01.006

Liu, Z. (2005). Reading behavior in the digital environment: Changes in reading behavior over the past ten years. The Journal of Documentation, 61(6), 700-712. doi:10.1108/00220410510632040

Lund, A., \& Lund, M. (2013). Testing for normality using SPSS statistics. Laerd Statistics. Retrieved from https://statistics.laerd.com/spss-tutorials/testing-for-normality-using-spss-statistics.php

McGill, T. J., Klobas, J. E., \& Renzi, S. (2011). LMS use and instructor performance: The role of task-technology fit. International Journal on E-Learning, 10(1), 43-62.

McKelvain, B. (2011). Joint bell labs - ACU usability study of a digital book interface. ACU Connected, Abilene, TX. Retrieved from: http://www.acu.edu/technology/mobilelearning/documents/research/bell-labs-report.pdf

Morrone, A. \& Dennis, A. (2010). ETextbook use and relationships with course performance, motivation, and attitudes. Academic Press.

Muthen, B., \& Kaplan, D. (1985). A comparison of some methodologies for the factor analysis of nonnormal likert variables. British Journal of Mathematical \& Statistical Psychology, 38(2), 171-189. doi:10.1111/j.2044-8317.1985.tb00832.x

Norris, A. E., \& Aroian, K. J. (2004). To transform or not transform skewed data for psychometric analysis: That is the question! Nursing Research, 53(1), 67-71. doi:10.1097/00006199-200401000-00011 PMID:14726780

Peng, C. Y., Harwell, M., Liou, S. M., \& Ehman, L. H. (2006). Advances in missing data methods and implications for educational research. In S. Sawilowsky (Ed.), Real data analysis (pp. 31-78). Information Age.

Raven, A., Leeds, E., \& Park, C. W. (2010). Digital video presentation and student performance: A task technology fit perspective. International Journal of Information and Communication Technology Education, 6(1), 17-29. doi:10.4018/jicte.2010091102

Schafer, J. L. (1999). Multiple imputation: A primer. Statistical Methods in Medical Research, 8(1), 3-15. doi:10.1177/096228029900800102 PMID:10347857

Schugar, J. T., Schugar, H., \& Penny, C. (2011). A nook or a book: Comparing college students' reading comprehension level, critical reading, and study skills. International Journal of Technology in Teaching and Learning, 7(2), 174-192. 
Siegenthaler, E., Wurtz, P., \& Groner, R. (2010). Improving the usability of e-book applications. Journal of Usability Studies, 6(1), 25-38.

Stone, R. W. \& Baker-Eveleth, L. (2013a). Factors influencing students' likelihood to purchase electronic textbooks. Interdisciplinary Journal of E-Learning and Learning Objects, 9.

Stone, R. W., \& Baker-Eveleth, L. (2013b). Students' expectation, confirmation, and continuance intention to use electronic textbooks. Computers in Human Behavior, 29(3), 984-990. doi:10.1016/j.chb.2012.12.007

Sun, J., Flores, J., \& Tanguma, J. (2012). E-Textbooks and students' learning experiences. Decision Sciences Journal of Innovative Education, 10(1), 63-77. doi:10.1111/j.1540-4609.2011.00329.x

Tabachnick, B. G., \& Fidell, L. S. (2007). Using multivariate statistics. Pearson Education.

Torres, R., Johnson, V., \& Imhonde, B. (2014). The impact of content type and availability on eBook reader adoption. Journal of Computer Information Systems, 54(4), 42-51. doi:10.1080/08874417.2014.11645721

Wandersee, J. H. (1988). Ways students read texts. Journal of Research in Science Teaching, 25(1), 69-84. doi:10.1002/tea.3660250107

Wang, L., Fan, X., \& Willson, V. L. (1996). Effect of nonnormal data on parameter estimates and fit indices for a model with latent and manifest variables: An empirical study. Structural Equation Modeling, 3(3), 228-247. doi:10.1080/10705519609540042

Weisberg, M. (2011). Student attitudes and behaviors towards digital textbooks. Publishing Research Quarterly, 27(2), 188-196. doi:10.1007/s12109-011-9217-4

Wilson, C. S., D'Ambra, J., \& Drummond, R. (2014). Exploring the fit of e-books to the needs of medical academics in Australia. The Electronic Library, 32(3), 403-422. doi:10.1108/EL-09-2012-0118

Jo R. Jardina has a PhD in Human Factors Psychology from Wichita State University and a Master's in psychology from the University of Houston - Clear Lake. She is a Senior User Experience Researcher in the Interconnected Experience Group, where she focuses on the user experience of the e-commerce website at The Home Depot. During her time in the Software Usability Research Lab (SURL) she studied the user experience of mobile devices, especially in relation to educational technology. Examining the user experience of new and emerging technology peak her research interests.

Barbara S. Chaparro has a PhD in Experimental Psychology from Texas Tech University. She is a Professor in the Human Factors and Behavioral Neurobiology Department and head of the Research in User eXperience (RUX) Lab at Embry-Riddle Aeronautical University. She is the former Program Chair of the Human Factors Psychology doctoral program at Wichita State University and director of the Software Usability Research Lab (SURL). Her research interests include the study of factors that influence the user experience (UX) of products and systems, the investigation of usability assessment methods, and the efficacy of mobile computing devices.

Sue Abdinnour Omer is Professor and Kansas Faculty of Distinction in the Barton School of Business at Wichita State University. She is also the Director of the Business Operations and Analytics Lab. She received her Ph.D. from Indiana University, Bloomington and her M.Sc. from University of Southampton, UK. Her research interests include Operations Management, Supply Chain Management, Information Systems, and Human Factors. She published her research in elite academic and practitioner journals and attended numerous local, national, and international conferences during her career. She teaches at the undergraduate and graduate levels. In addition to research and teaching, Sue is very active in her professional societies and serves on many advisory boards. 